\title{
Bottom-up Links to Juvenile Salmon Growth and Survival in Puget Sound, WA, USA
}

\author{
Julie E. Keister ${ }^{1}$, Amanda K. Winans ${ }^{1}$, BethEILee Herrmann¹, Julia Bos², and Iris Kemp ${ }^{3}$ \\ ${ }^{1}$ School of Oceanography, College of the Environment, University of Washington, Seattle, WA 98195, USA \\ ${ }^{2}$ Washington Department of Ecology, Olympia, WA, USA \\ ${ }^{3}$ Long Live the Kings, Seattle, WA, USA
}

Keywords: Zooplankton, juvenile salmon, Puget Sound, climate variability

Over the past several years, the Northeast Pacific has experienced a broad range of conditions ranging from "normal" to unprecedented warm temperature anomalies. Such extreme climate variability had clear impacts on the biology and provided the opportunity to explore the mechanisms through which large-scale climate change influences salmon through bottom-up processes. We used data from several monitoring programs in the Strait of Juan de Fuca and Puget Sound to explore spatial and interannual variability in ecosystem response to environmental change over 2014-2017. We focus on changes in temperature and zooplankton relationships to juvenile salmon growth and survival in four regions, from north to south: the San Juan Islands, Admiralty Inlet, Central Basin, and South Sound.

Monthly CTD casts have been conducted since 1997 by the Washington Dept. of Ecology to measure temperature, salinity, and fluorescence. The fluorometer was calibrated to chlorophyll biomass using filtered Niskin water samples at each station. Zooplankton were collected bi-weekly in spring through fall of 2014-2017 by multiple partners using $60-\mathrm{cm}$ diameter, $200-\mu \mathrm{m}$, full water-column vertical net tows. Biomass was calculated using carbon conversions from abundances of taxa identified in the laboratory to species and life stage. Juvenile salmon growth was calculated from the change in weight over the time from hatchery release to recapture on Canada Department of Fisheries and Oceans R/V Ricker trawl surveys conducted in Puget Sound once per summer in most years since 1999. Smolt-to-adult coho survival data were calculated by M. Alexandersdottir under a contract from the Tulalip Tribes from coded wire tag returns (available only through 2015).

Temperatures showed strong seasonal cycles and a latitudinal gradient from cooler in the north where there is more connection to the ocean, to warmer in the more isolated regions to the south. The coolest year overall at all sites was 2014; 2015 and 2016 were record-breaking warm; 2017 was cooler, with Central and South Basin remaining slightly warmer than in 2014 while the San Juan Islands and Admiralty Inlet sites returned to approximately 2014 temperatures. Chlorophyll biomass was highest in Admiralty Inlet and Central Basin where spring and fall blooms occurred in most years. There were mixed interannual patterns among sites: in Central Basin chlorophyll was highest in 2014 and 2017, and considerably lower in 2015-2016. Chlorophyll was relatively low in the San Juan Islands and South Sound, and differences among years were not as apparent there.

Cumulative total zooplankton biomass curves showed spatial and temporal differences. In all regions, biomass was lowest in 2014 and higher in 2015. This was also true for all taxa that are important juvenile salmon prey (crab larvae, amphipods, etc.). In the San Juan Islands where biomass was relatively low overall, biomass peaked in 2015 whereas at the other stations, biomass was even higher in 2016. In 2017, biomass was lower at the northern two sites, but stayed high at the Central and South sites where water temperatures also stayed relatively warm.

Growth of juvenile Chinook salmon from hatcheries in Puget Sound showed a clear relationship with sea surface temperature anomalies measured at Race Rocks Lighthouse, which also correlates with the Pacific Decadal Oscillation. Regions showed strong spatial coherence, with highest growth observed in the very warm years of 2005 and 2015-2016, and low growth during cool periods. Coho salmon smolt-to-adult survival was higher for fish that out-migrated during the warm year of 2015 compared to 2014 in nearly every stock calculated across Puget Sound. Survival data are not yet available for Chinook salmon or for years beyond 2015, but anecdotes of poor 2017 returns indicate that future cohorts did not survive as well, despite continued high zooplankton biomass in most regions of Puget Sound.

In conclusion, the large interannual differences in temperature had strong effects on plankton phenology, biomass, and community structure with responses differing among local sub-basins of Puget Sound. In contrast to expectations, during the warm years, zooplankton biomass and juvenile salmon growth were strongly elevated, and returns of 2015 coho salmon outmigrants indicated relatively high survival. This contrasts with reports from the Washington and Oregon coast and demonstrates the need for monitoring and indicator development within Puget

All correspondence should be addressed to J. Keister. 
Sound to better forecast salmon returns. High temperatures and sufficient food during their critical early marine life stage may have contributed to high growth and over-winter survival of salmon. But returns of subsequent years' cohorts suggests that something other than Puget Sound conditions controlled survival—possibly Pacific Ocean conditions were too poor for adult salmon to overwinter.

Acknowledgments - This study was conducted as part of the Salish Sea Marine Survival Project (SSMSP).

Zooplankton samples were collected by Kwiáht (San Juan Islands), the Port Gamble S'Klallam Tribe and WA Dept. of Fish and Wildlife (Admiralty Inlet), King County (Central Basin), and the Nisqually Indian Tribe (South Sound). Funding for the zooplankton sampling and this analysis came from the SSMSP via Long Live the Kings, NOAA via the Tulalip Tribes, the WA Dept. of Natural Resources, and the University of Washington. 